\title{
Chemically-Modified Curcumin 2.24: A Novel Systemic Therapy for Natural Periodontitis in Dogs
}

This article was published in the following Dove Press journal: Journal of Experimental Pharmacology

\author{
Jie Deng (D) \\ Lorne M Golub' \\ Hsi-Ming Lee' \\ Michael C Lin' \\ Heta Dinesh Bhatt ${ }^{\prime}$ \\ Hou-Lin Hong ${ }^{2}$ \\ Francis Johnson ${ }^{3}$ \\ Joseph Scaduto (iD) \\ Thomas Zimmerman (iD ${ }^{5}$ \\ Ying $\mathrm{Gu}^{6}$ \\ 'Department of Oral Biology and \\ Pathology, School of Dental Medicine, \\ Stony Brook University, Stony Brook, NY \\ I I794, USA; ${ }^{2}$ Department of Public \\ Health, School of Medicine, Stony Brook \\ University, Stony Brook, NY I I794, USA; \\ ${ }^{3}$ Department of Chemistry and \\ Pharmacological Sciences, School of \\ Medicine, Stony Brook University, Stony \\ Brook, NY II794, USA; ${ }^{4}$ Traverse \\ Biosciences, Inc., Stony Brook, NY \\ 1 1790, USA; ${ }^{5}$ Division of Laboratory \\ Animal Resources (DLAR) at Stony \\ Brook, Stony Brook University, Stony \\ Brook, NY II794, USA; ' Department of \\ General Dentistry, School of Dental \\ Medicine, Stony Brook University, Stony \\ Brook, NY II794, USA
}

Correspondence: Jie Deng

Department of Oral Biology and Pathology, School of Dental Medicine, Stony Brook University, Stony Brook, NY 11794, USA

Tel $+\mid 646$ 7I5-2925

$\mathrm{Fax}+\mid$ 631 632-9705

Email jie.deng917@gmail.com
Purpose: To determine the effect of a pleiotropic MMP-inhibitor, a novel chemicallymodified curcumin 2.24 (CMC2.24), on the clinical and biological measures of naturallyoccurring periodontitis in the beagle dog.

Methods: Eight adult female dogs with generalized periodontitis were distributed into two groups: Placebo and Treatment ( $\mathrm{n}=4$ /group). After a 1-hr full-mouth scaling and root planing (SRP) at time 0 , placebo or CMC2.24 $(10 \mathrm{mg} / \mathrm{kg})$ capsules were orally administered once/day for 3 months. Various clinical periodontal parameters (e.g., pocket depth, gingival index) were measured at different time periods ( $0,1,2$ and 3 months), and gingival crevicular fluid (GCF) samples and gingival tissue biopsies (3-month) were analyzed for cytokines, MMPs and cell-signaling molecules. Standardized radiographs were taken at 0 and 3-month; in addition, peripheral blood monocytes/macrophages from these dogs at 3-month were cultured and analyzed for the pro-, activated-, and total-forms of both MMP-2 and MMP-9.

Results: CMC2.24 treatment significantly reduced gingival inflammation (gingival index, GCF flow), pocket depth (PD), and the numbers of pockets (PD $\geq 4 \mathrm{~mm}$ ), compared to placebo. CMC2.24 also significantly reduced MMP-9 and MMP-2 (primarily in the activated-form) in gingival tissue, alveolar bone loss, and reduced GCF IL-1 $\beta$. Cell-signaling molecules, TLR-2 (but not TLR-4) and p38 MAPK, responded to CMC2.24 in a pattern consistent with reductions in inflammation and collagenolysis. In culture, CMC2.24 had no effect on pro-MMP-9 but essentially completely blocked the conversion of pro- to activatedMMP-9 in systemic blood-derived monocytes/macrophages from these dogs.

Conclusion: In the beagle dog model of natural periodontitis, orally administered CMC2.24 (a novel triketonic phenylaminocarbonyl-curcumin) significantly decreased clinical measures of periodontitis as well as pro-inflammatory cytokines, MMPs, and cell-signaling molecules. These and previous studies, using other in vitro and in vivo models, support the clinical potential of CMC2.24 as a novel adjunct to SRP in the treatment of chronic periodontitis.

Keywords: periodontitis, bone loss, chemically modified curcumin, matrix metalloproteinases, host-modulation therapy

\section{Introduction}

Periodontitis, a most common chronic inflammatory disease, is initiated by a wellcharacterized microbial biofilm (primarily involving anaerobic gram-negative bacteria including Porphyromonas gingivalis, Tannerella forsythia, Prevotella intermedia and others), followed by connective tissue breakdown including alveolar bone loss mediated by the host response. ${ }^{1-3}$ The latter is characterized by the generation of inflammatory mediators, such as Interleukin-1 beta (IL-1 $\beta$ ), Interleukin-6 (IL-6), tumor necrosis 
factor-alpha (TNF- $\alpha$ ), Prostaglandin $\mathrm{E}_{2}\left(\mathrm{PGE}_{2}\right)$, and the excessive production of collagenolytic enzymes, including the matrix metalloproteinases (MMPs; especially MMP-8, MMP-9, MMP-12 and MMP-13). ${ }^{2,4,6}$ Clinically, this biologic cascade results in the loss of the periodontal attachment apparatus, including apical migration of the epithelial attachment, formation of periodontal pockets, and loss of alveolar bone. ${ }^{5}$ This widely accepted pathologic cascade provides the rationale for a pharmacologic strategy developed more than three decades ago (and recently reviewed by Golub and Lee), ${ }^{6}$ titled "Host Modulation Therapy" or "HMT". 7-9 This treatment strategy evolved from the discovery that tetracyclines (a group of antibiotics commonly prescribed for bacterial infections), unexpectedly, inhibited host-derived MMPs, and by NON-antimicrobial host-modulating mechanisms unrelated to their well-characterized antibiotic activity. This discovery "drove" the development of novel, NON-antibiotic "formulations" and (later) "compositions" of tetracyclines which could be administered as host-modulators without producing the side-effect of antibiotic-resistant bacteria. The NONantibiotic "formulations" include "low-dose" doxycycline (20 mg b.i.d., and sustained-release $40 \mathrm{mg}$ q.d.); ${ }^{10}$ and many NON-antimicrobial "compositions" of these drugs. However, of the latter group, only one has been studied extensively, the chemically-modified tetracycline molecule, CMT-3 (i.e., 6-demethyl 6-deoxy 4-dedimethylamino tetracycline). ${ }^{9-15}$ It should be noted that both of the former formulations are government-approved (US Food and Drug Administration; also Canada and Europe governmental agencies), while the latter (CMT-3) has been tested in human clinical trials in patients with a type of angiogenic cancer and in other malignancies, and in preliminary studies on patients with chronic periodontitis. ${ }^{6,11-15}$ Although these NON-antibiotic tetracycline-based HMTs primarily function as inhibitors of MMPs, they also exhibit pleiotropic anti-inflammatory activity by down-regulating inflammatory cytokines, prostanoids, and reactive oxygen species (e.g., superoxide anion, hypochlorous acid). ${ }^{7,11,16}$

A second category of HMTs which have been widely studied, are the resolvins. ${ }^{17,18}$ These are derivatives of omega-3 fatty acids, docosahexaenoic acid (DHA), eicosapentaenoic acid (EPA), and the lipoxins. ${ }^{17,19-27}$ These novel compounds have demonstrated safety and efficacy as HMTs and function by preventing the destructive prolongation, or chronicity, of the inflammatory response, but do not block its acute phase which is necessary to combat infections. 9,28,29 However, none of these formulations has been governmentapproved as therapeutic agents for periodontitis at this time.

More recently, our group has developed a newer series of HMTs, which incorporate a similar, metal-ion $\left(\mathrm{Ca}^{2+}, \mathrm{Zn}^{2+}\right)$ binding-active site, like the NON-antibiotic tetracyclines, but which are bi- and tri-phenolic rather than tetra-phenolic, i.e., the bis-aroyl methanes (BAMs) (now abandoned) and the novel chemically-modified curcumins (CMCs). ${ }^{30,31}$ Of these (Figure 1), CMC2.24 (a phenylaminocarbonyl curcumin), the "lead" compound, was found to be safe and most effective based on in vitro, cell and tissue culture, and in vivo studies on rat models of experimental periodontitis, diabetes, and wound healing. ${ }^{30-38}$ Moreover, this novel compound is tri-ketonic (see "circle" below) rather than di-ketonic (see
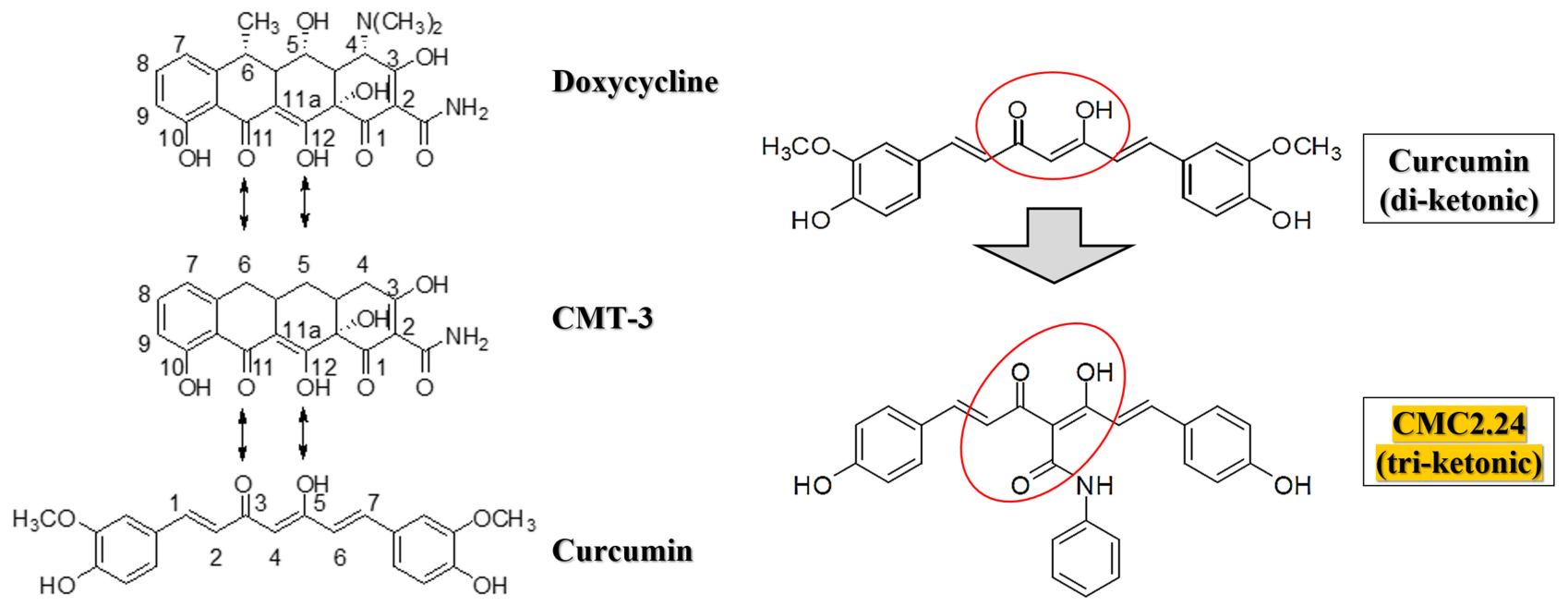

\section{CMC2.24 \\ (tri-ketonic)}

Figure I Structures of doxycycline, chemically modified tetracycline-3 (CMT-3), curcumin, and a chemically modified curcumin, CMC2.24. All these bi- and tetra-phenolic compounds possess the cation-binding $\beta$-diketone moiety at the C-4 position (as "circled" and illustrated on the right top) (note that the highlighted tri-phenolic CMC2.24 is also tri-ketonic as "circled" on the right bottom while the other compounds are di-ketonic). 
"circle" below) providing a structural mechanism (increased cation-binding) for its enhanced potency as an MMPinhibitor. $^{30-32}$

Previous studies have demonstrated the efficacy of CMC2.24 to reduce inflammatory cytokines and to inhibit bone loss in diseases such as periodontitis in small (rodent) animal models. In the current study, a large (dog) animal model with naturally-occurring periodontitis was used to further define the pleiotropism of CMC2.24, as a hostresponse modulator, in reducing inflammation/collagenolysis, and this animal model is widely recognized as necessary before progressing to human clinical trials. The aim of current study is to determine the in vivo effects of CMC2.24 on the clinical and biological measures of periodontitis in the dog, and to further examine its underlying mechanisms on the inflammatory cell-signaling pathway by inhibiting of cell-signaling molecules Toll-Like Receptor-2 (TLR-2) and p38 Mitogen-Activated Protein Kinase (p38 MAPK) expressions. Regarding the null hypothesis of our study, there is no difference or no relationship in efficacy between the treatment and placebo groups.

\section{Materials and Methods}

\section{Chemical Reagents}

CMC 2.24 was synthesized and provided by Chem-Master Intl., Inc. (99.5\% pure, Stony Brook, NY, USA). Carboxymethylcellulose as placebo was purchased from Sigma Chemical Co. (St Louis, MO, USA). All cell culture reagents and other chemical reagents were purchased from Thermo Fisher Scientific (Waltham, MA, USA).

\section{Animal Studies}

Protocols for the animal studies were approved by Stony Brook University's Institutional Animal Care and Use Committee (IACUC \#896357). Animals were housed in the Division of Laboratory Animal Resources (DLAR) at Stony Brook University, with care provided by the center's personnel. All procedures were conducted at the same location. This facility follows the Animal Welfare Act (USDA enforced), the Public Health Service Act (OLAW enforced), and NY State law (DOH enforced), and is an AAALAC International accredited facility.

Eight adult female beagle dogs (3-5 years old, 9.5-11.5 kg) with generalized periodontitis were supplied by Marshall BioResourses (5800 Lake Bluff Rd, North Rose, NY), after preliminary screening of 49 similar dogs for significant periodontal disease in their posterior teeth. Exclusion criteria of dogs included pregnancy, health or laboratory abnormalities, and previously used within 3 months in another study.

The dogs were single-housed in standard kennels with ambient temperature maintained at $18-24^{\circ} \mathrm{C}$ and lights automatically turned on/off at 06:00 AM/18:00 PM. All dogs were acclimatized to the study environment two weeks prior to the initiation of the experiment.

\section{Study Design}

Data collection to test the efficacy of drug was analyzed at four-time points as described below (Figure 2). During all exams, procedures and sample collections, the dogs were administered general anaesthesia. Anaesthesia was performed by veterinarians in the DLAR. At each time point, food/water was removed from cages $12 \mathrm{hrs}$ before anesthesia.

At pre-baseline, a pretreatment full-mouth exam was performed one week prior to baseline data collection. Periodontal measurements including the following clinical parameters were taken: probing depth (PD), gingival index (GI), plaque index (PII), bleeding-on-probing (BOP), clinical attachment loss (CAL) and tooth mobility. These measurements were made at all posterior sites of the maxillary and mandibular teeth using a UNC-15 periodontal probe (Hu-Friedy, Chicago, USA) as described below. Based upon the clinical periodontal measurements (PD, GI, PII, BOP, CAL, tooth mobility, and number of sites with deep pockets), dogs with generalized moderate to severe periodontitis were equally distributed into placebo and treatment groups ( $n=4 /$ group), to ensure a similar level of disease in both groups.

\section{Baseline}

At time $=0$, the weight of each dog was recorded, and blood samples were collected. Clinical photos and standardized radiographs of the jaws were also taken. Gingival crevicular fluid (GCF) samples were collected at the selected pocket sites with $\mathrm{PD} \geq 5 \mathrm{~mm}$ (4-8 sites/dog) as described below. Then, periodontal disease severity was assessed using clinical parameters: PII, GI, PD, BOP, CAL and mobility scores, which were recorded for all posterior teeth in both jaws (see following sections). After sample and data collections, all eight dogs received a standard non-surgical periodontal treatment. Briefly, a one-hour full mouth scaling and root planing (SRP) was performed with an ultrasonic scaler (Parkell Inc, Edgewood, NY, USA) and hand instrumentation as needed for calculus and plaque removal until all deposits were 


\section{Timeline: 4 Time Points}

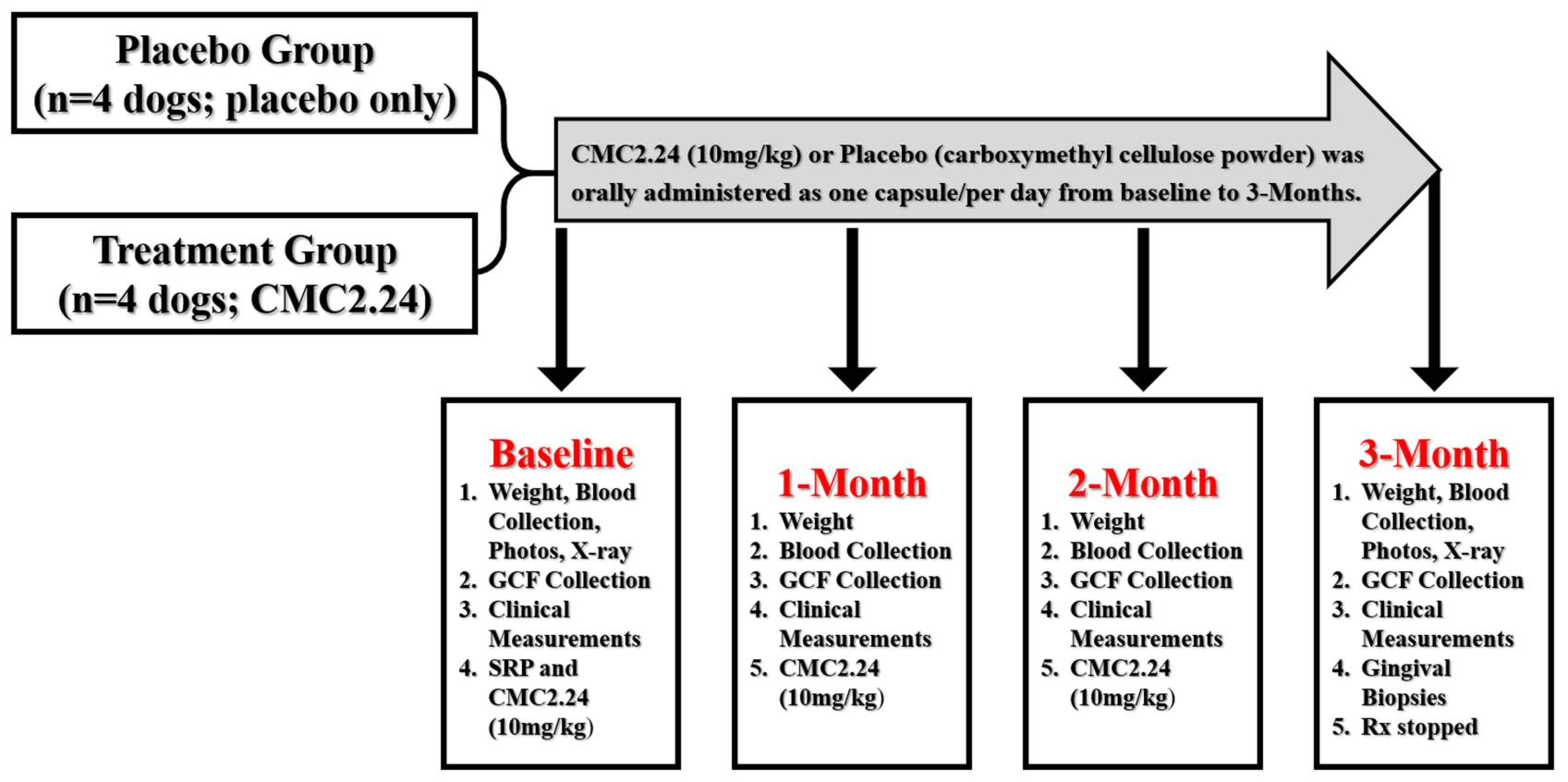

Figure 2 Schema describing the longitudinal protocol.

undetectable clinically. After SRP, one capsule containing either CMC2.24 (10mg/kg in the same vehicle) or placebo (vehicle only: carboxymethylcellulose powder) was administered orally once/day to each dog for three months. Food/water was removed from cages two hours before and after systemic application.

\section{One- and Two-Months' Time Periods}

The weight for each dog was recorded and blood samples were collected at each time period. GCF collection and periodontal clinical measurements were performed as described in the baseline section.

\section{Three Months' Time Periods}

In addition to the procedures described in the previous section, clinical photos and standardized dental radiographs were taken at this final time period. After GCF collection and periodontal clinical measurements were obtained, two gingival biopsies/dog, approximate $5 \times 2 \times 1 \mathrm{~mm}^{3}$ per piece, were collected with a sterile surgical scalpel. Gingival biopsy specimens were excised from preselected sites with deep pockets then stored at $-80^{\circ} \mathrm{C}$ for future extraction, partial purification, and analyses of MMPs (gelatin zymography) and cell-signaling molecules (Western blot), as described below. At the end of this time period, oral administration of $\mathrm{CMC} 2.24$ or placebo was stopped.
All measurements were performed in a blinded fashion, that is the clinical examiner did not know which group was receiving placebo or $\mathrm{CMC} 2.24$, and the investigators (2 people) carrying out the data analysis also did not know which group was receiving placebo or $\mathrm{CMC} 2.24$. On completion of the in vivo protocol, all dogs were successfully arranged for adoption by Stony Brook University Animal Care Facility.

\section{Clinical Measurements}

Clinical parameters (PII, GI, PD, BOP, and CAL) were measured at all time periods ( $0,1,2$, and 3 months).

\section{Probing Depth (PD)}

All posterior sites (3 buccal and 3 lingual/palatal sites per tooth) were measured at each time period. First, periodontal pockets with initial probing depth $\geq 4 \mathrm{~mm}$ were monitored at all time periods (time $=0,1,2$ and 3 months). Second, the total numbers of deep pockets ( $\mathrm{PD} \geq 4 \mathrm{~mm}$ ) at each time period were also recorded.

\section{Gingival Index (GI)}

All posterior gingival sites (2 sites/tooth, 1 buccal and 1 lingual/palatal sites) were recorded on a scale of 0 to 3 at each time period, based on the scoring criteria described in Table 1 . Then, the total numbers of severely inflamed gingival sites $(\mathrm{GI} \geq 2)$ at each time period were measured. 


\section{Plaque Index (PII)}

All posterior tooth surfaces ( 2 surfaces/tooth, 1 buccal and 1 lingual/palatal surfaces) were recorded on a scale of 0 or 1 at each time period, based on the scoring criteria described in Table 2. Then, the total numbers of tooth surfaces with clinically visible plaque $(\mathrm{PII}=1)$ at each time period were measured.

\section{Bleeding-on-Probing (BOP)}

All posterior teeth (3 buccal and 3 lingual/palatal sites per tooth) were assessed as absence (-) or presence of bleeding $(+)$ after probing at each time period. For each dog, number of sites with bleeding $(+)$ was recorded.

\section{Clinical Attachment Loss (CAL)}

CAL is defined as CAL $=$ PD-CEJ.GM, where CEJ.GM refers to the distance $(\mathrm{mm})$ from the cementoenamel junction to the gingival margin.

\section{GCF Collection and Extraction Collection}

GCF was collected before probing depth was measured to avoid irritation of the gingiva at the selected pocket sites

Table I The Scoring Criteria of Gingival Index (GI)

\begin{tabular}{|l|l|}
\hline $\mathrm{Gl}=0$ & Normal gingiva \\
\hline $\mathrm{Gl}=\mathrm{I}$ & $\begin{array}{l}\text { Mild inflammation. Characterized by slight change in color } \\
\text { and slight edema, and no bleeding when a blunt instrument } \\
\text { (periodontal probe) is run along the soft tissue entrance of } \\
\text { the gingival crevice. }\end{array}$ \\
\hline $\mathrm{Gl}=2$ & $\begin{array}{l}\text { Moderate inflammation. Characterized by redness, edema } \\
\text { and glazing, and bleeding when a blunt instrument } \\
\text { (periodontal probe) is run along the soft tissue entrance of } \\
\text { the gingival crevice. }\end{array}$ \\
\hline $\mathrm{Gl}=3$ & $\begin{array}{l}\text { Severe inflammation. Characterized by marked redness and } \\
\text { edema. Ulceration may be present and there is marked } \\
\text { tendency for spontaneous bleeding (i.e. on gentle palpation of } \\
\text { the gingiva with the side of a probe. }\end{array}$ \\
\hline
\end{tabular}

Note: Data from these studies. ${ }^{48,59}$

Table 2 The Scoring Criteria of Plaque Index (PII)

\begin{tabular}{|l|l|}
\hline$P I I=0$ & No visible plaque in the gingival area \\
\hline$P I=I$ & $\begin{array}{l}\text { A film of plaque adhering to the free gingival margin and } \\
\text { adjacent area of the tooth. The plaque may only be } \\
\text { recognized by running a probe across the tooth surface; or } \\
\text { may be visible to the naked eye. }\end{array}$ \\
\hline
\end{tabular}

Note: Data from Yiman et al. ${ }^{48}$

Abbreviations: $\mathrm{Gl}$, gingival index; Pll, plaque Index. with $\mathrm{PD} \geq 5 \mathrm{~mm}(4-8$ sites $/ \mathrm{dog})$. The area for GCF collection was isolated with cotton rolls to prevent saliva contamination and dried with sterile gauze sponges. A Periopaper ${ }^{\circledR}$ strip (Oraflow Inc, Hewlett, NY, USA) was inserted to the depth of the selected pocket and left in place for $10 \mathrm{~s}$. GCF was immediately measured using a calibrated Periotron ${ }^{\circledR} 6000$ (Oraflow Inc, Hewlett, NY, USA) according to the manufacturer's instructions. After collection, the samples were immediately placed into tubes on ice $\left(4^{\circ} \mathrm{C}\right)$ and stored at $-80^{\circ} \mathrm{C}$ until further analysis.

\section{Extraction}

The frozen GCF samples were thawed $\left(4^{\circ} \mathrm{C}\right)$ for 15 mins. Then, $400 \mu \mathrm{L}$ of $50 \mathrm{mM}$ Tris/ $0.2 \mathrm{M} \mathrm{NaCl} / 5 \mathrm{mM} \mathrm{CaCl}_{2}$ buffer (pH 7.6), containing a proteinase-inhibitor cocktail (which blocks serine, cysteine, and thiol proteinases, but not MMPs), consisting of antipain ( $1 \mathrm{mg} / \mathrm{L})$, aprotinin $(1 \mathrm{mg} / \mathrm{L})$, N-ethylmaleimide (125 mg/L), leupeptin (1 mg/L), and $50 \mathrm{mg} / \mathrm{L}$ detergent, was added to the GCF samples. The strips containing the GCF were exhaustively mixed and extracted $\left(1 \mathrm{hr}, 4^{\circ} \mathrm{C}\right)$ as described previously, ${ }^{39,40}$ and aliquots were taken for analysis of inflammatory mediators by ELISA.

\section{Radiographic Analysis of Alveolar Bone Loss}

Standardized intraoral periapical radiographs at selected sites were taken at baseline and 3 months. A parallel-projection technique was used to position the X-ray sensor so that the beam exposes both the tooth and the X-ray sensor at right angles, resulting in minimal geometric distortion. A standardized probe was placed adjacent to the tooth to calculate the alveolar bone loss. ${ }^{41}$ Radiographic measurements were analyzed by image $\mathrm{J}$ software to assess alveolar bone loss by measuring the distance from a fixed-anatomical landmark, the cementoenamel junction (CEJ), to the alveolar bone crest (ABC). Briefly, the distance from CEJ to $\mathrm{ABC}$ was calculated using the equation: $\mathrm{HR}_{1}: \mathrm{HX}_{1}=\mathrm{HR}_{2}: \mathrm{HX}_{2}\left(\mathrm{HR}_{1}\right.$ : height of real probe; $\mathrm{HR}_{2}$ (unknown): height of real alveolar bone loss; $\mathrm{HX}_{1}$ : height of radio-opaque probe; $\mathrm{HX}_{2}$ : height of radio-opaque alveolar bone loss). All measurements were analyzed using a radio-opaque probe as an internal standard control. ${ }^{42,43}$

\section{Gingival Tissue Extraction and Partial Purification}

Two biopsies of gingival tissues from each dog at the threemonth time point were collected as described above. During the extraction process, all procedures were performed at $4^{\circ} \mathrm{C}$. One of two gingival tissues from each dog was homogenized 
and the MMPs partially purified as described by us previously. ${ }^{33,37}$ In brief, gingival tissues were homogenized with a glass grinder (Kontes, Glass Co., Vineland, NJ, USA) attached to a T-Line Lab stirrer (Model 106 Taboys Engineering Corp., NJ, USA) in $50 \mathrm{mM}$ Tris- $\mathrm{HCl}$ buffer ( $\mathrm{pH} 7.6$ ) containing $5 \mathrm{M}$ urea, $0.2 \mathrm{M} \mathrm{NaCl}$, and $5 \mathrm{mM} \mathrm{CaCl}_{2}$, then extracted overnight and centrifuged at 15,000 rpm for $1 \mathrm{~h}$. The supernatants were collected and dialyzed exhaustively against $50 \mathrm{mMT}$ Tis buffer $(\mathrm{pH} 7.8$ ) containing $0.2 \mathrm{M}$ $\mathrm{NaCl}$ and $5 \mathrm{mM} \mathrm{CaCl}_{2}$. Ammonium sulfate was added to the dialysate to produce $60 \%$ saturation, allowed to stand overnight, and the precipitate containing the MMPs was collected by centrifugation at $15,000 \mathrm{rpm}$ for $90 \mathrm{~min}$. The pellets were then dissolved in the Tris buffer ( $\mathrm{pH} 7.8$ ) containing $\mathrm{NaCl}$, $\mathrm{CaCl}_{2}$, and $0.05 \%$ Brij and exhaustively dialyzed against the same buffer. Protein content of the extracts was determined by Bio-Rad Protein Assay. The levels of MMPs in the gingival extracts were analyzed by gelatin zymogram; and the expressions of cell-signaling molecules were analyzed by Western blot as described below.

\section{Peripheral Blood Monocyte/Macrophage Culture (ex-vivo)}

At the three-month time period, blood samples were taken from the 8 dogs with periodontitis, which were systemically treated with CMC2.24 or placebo. $10 \mathrm{~mL}$ of whole blood from each dog was drawn, then transferred to tubes coated with heparin (anti-clotting). Monocyte/macrophage isolation was conducted by density gradient centrifugation using Lymphoprep $^{\mathrm{TM}} \quad$ (Accurate Chemical \& Scientific Corporation, Westbury, NY, USA) at a ratio of 2 to $1-1.5$ $(\mathrm{v} / \mathrm{v})$ and centrifuged at $1800 \mathrm{rpm}$ for $30 \mathrm{~min}$ at $25^{\circ} \mathrm{C} .44$ Monocytes/macrophages were then isolated and cultured 18 hrs in 24-well plates with Serum-Free Medium (SFM) (Thermo Fisher Scientific Inc., USA). Each well contained $10^{6}$ cells, supplemented with 100 units $/ \mathrm{mL}$ penicillin, $100 \mu \mathrm{g} /$ $\mathrm{mL}$ streptomycin, in a humidified atmosphere of $5 \% \mathrm{CO}_{2}$ and $95 \%$ air at $37^{\circ} \mathrm{C}$. After $18 \mathrm{hrs}$, supernatants were collected and analyzed for MMP-9 activity.

\section{Gelatin Zymography}

Assays for MMP-2 (pro-form: $72 \mathrm{kDa}$; activated-form: 63 $\mathrm{kDa}$ ) and MMP-9 (pro-form: $92 \mathrm{kDa}$; activated-form: 82 $\mathrm{kDa}$ ) in gingival tissue and cultured medium of macrophages isolated from peripheral blood (ex-vivo) were described by us previously. ${ }^{12,33,37,45}$ In brief, the gelatin zymography system and sodium dodecyl sulfate- (SDS-) polyacrylamide gels (PAGE) containing polyacrylamide copolymerized with gelatin at a final concentration of $1 \mathrm{mg} / \mathrm{mL}$ were purchased from Invitrogen Corp. (Carlsbad, CA, USA). After electrophoresis (120V), the gels were rinsed with distilled water and soaked in $(1 \times)$ Novex ${ }^{\mathrm{TM}}$ zymogram renaturing buffer (LC2670, Thermo Fisher Scientific, Inc., Waltham, MA, USA) containing $2.5 \%$ Triton X-100 for 30 mins, and incubated at $37^{\circ} \mathrm{C}$ overnight in $(1 \times)$ Novex $^{\mathrm{TM}}$ zymogram developing buffer (LC2671, Thermo Fisher Scientific, Inc., Waltham, MA, USA) containing $40 \mathrm{mMTris} / \mathrm{HCl}, 200 \mathrm{mMNaCl}, 10 \mathrm{mM} \mathrm{CaCl}_{2}$, and $\mathrm{pH}$ 7.5), and then stained with Coomassie Brilliant Blue R-250 (Thermo Fisher Scientific, Inc., Waltham, MA, USA). As described by us earlier, ${ }^{32,33}$ clear zones of lysis against a blue background indicated gelatinolytic activity and were scanned densitometrically with Invitrogen ${ }^{\mathrm{TM}}$ iBright $^{\mathrm{TM}}$ FL1000 Imaging Systems (Thermo Fisher Scientific, Inc., (Thermo Fisher Scientific, Inc., Waltham, MA, USA) for protein gels, and analyzed by Image $J$ to assess quantitatively gelatinase activity. ${ }^{36}$ MMP-2 and MMP-9 standards were purchased from R\&D Systems, Inc. (Minneapolis, MN, USA).

\section{ELISA Assay}

ELISA kits for IL-1 $\beta$ (Catalog\# DY3747), IL-6 (Catalog\# CA6000), and TNF- $\alpha$ (Catalog\# CATA00) were purchased from R\&D Systems, Inc. (Minneapolis, MN, USA). The high-sensitivity CRP kit (Catalog\# MBS704226) was purchased from MyBioSource, Inc. (San Diego, CA, USA). All cytokine measurements were performed according to manufacturer's instructions.

\section{Western Blot Analysis}

Gingival samples were treated with RIPA buffer ( $\mathrm{pH} 7.0$ ) (R0278-50ML, Sigma-Aldrich, Inc. USA) containing Halt ${ }^{\mathrm{TM}}$ Protease and Phosphatase Inhibitor Cocktail, EDTA-free (1:100, 78,441, Thermo Scientific ${ }^{\mathrm{TM}}$, USA). Prestained Protein Standards, Precision Plus Protein ${ }^{\mathrm{TM}}$ Kaleidoscope ${ }^{\mathrm{TM}}$ (1,610,375, Bio-Rad Laboratories, Inc., USA) were used as molecular weight markers. The samples were electrophoresed on SDS-PAGE ( $8 \%$ separating and $4 \%$ stacking gels) and then electrophoretically transferred to nitrocellulose membranes. Western blot analysis was carried out as described by us previously. ${ }^{36}$ Specific immunoreactivity was visualized as dark bands against a clear background, and the membranes were scanned with Invitrogen ${ }^{\mathrm{TM}}$ iBright $^{\mathrm{TM}}$ FL1000 Western Blot Imaging Systems (Thermo Fisher Scientific, Inc., USA) for imaging and documenting chemiluminescent Western blot 
bands. The densitometric units were measured in the linear range of immunoreactivity for TLR-2 and p38 MAPK expressions by Image $\mathbf{J}$ analysis software.

\section{Statistical Analysis}

Cytokines, MMP levels, protein expressions and alveolar bone loss of both placebo and treatment groups were analyzed by Student's $t$-test, and also by ANOVA (two investigators carried out the data analysis, separately), with $\mathrm{p}<0.05$ taken as statistically significant. All data analyses were performed with SPSS $^{\circledR}$ WIN 12.0.

\section{Results}

In this initial report on the efficacy of a novel chemically modified curcumin, $\mathrm{CMC} 2.24$, in dogs with naturallyoccurring periodontitis, statistically significant improvements were observed in all of the clinical parameters measured, and these are now described.

\section{Gingival Index (GI)}

The placebo-treated group did not show any reduction in gingival inflammation (numbers of severely inflamed gingival sites) at any time period, while the group that was treated with CMC2.24 appeared to show a progressive reduction in severely inflamed gingiva (gingival index) with time; and the $20 \%$ reduction at the 3 -month time period, in this group, was statistically significant $(\mathrm{p}<0.05)$ compared to the baseline values (Figure 3). Clinically, there appeared to be less redness, edema and glazing in the $\mathrm{CMC} 2.24$ treated group; when a blunt instrument (periodontal probe) was run along the soft tissue entrance of the gingival crevice/pocket, there appeared to be much less bleeding in the treatment group, clinical signs which were consistent with the gingival index data described above.

\section{Plaque Index (PII)}

After three months of daily oral administration of CMC2.24 or placebo, there was no difference in plaque index between the two groups, indicating little/no effect on the accumulation of the microbial biofilm (data not shown).

\section{Probing Depth (PD)}

Probing depth measurements in the placebo-treated control group not only showed no improvements over the 3-month protocol (Figure 4A and B), but also showed a statistically significant $(\mathrm{p}<0.05)$ increase in mean probing depth, compared to its own baseline at the 2-month time period. In contrast, CMC2.24 treatment significantly reduced mean probing depth by about $30 \%(\mathrm{p}<0.001)$ compared to the placebo group at all time periods (1, 2, and 3 months), or compared to its own baseline values $(\mathrm{p}<0.001)$ (Figure 4A) at each time period as well. In addition, the total numbers of pockets with $\mathrm{PD} \geq 4 \mathrm{~mm}$ were also significantly reduced by CMC2.24 treatment at the 2-month time period by more than $60 \%(\mathrm{p}<0.05)$, compared to placebo; as well as compared to its own baseline at both the 2- and 3-month time periods $(\mathrm{p}<0.05)$ (Figure 4B).

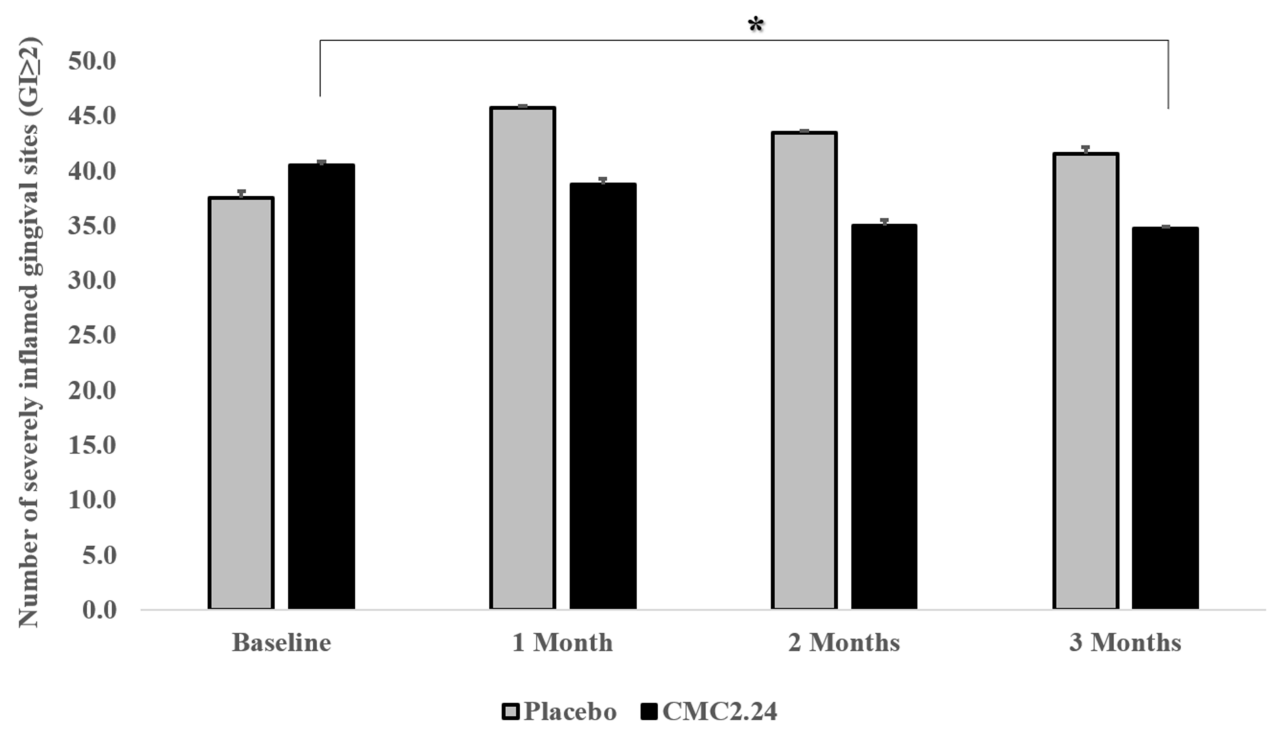

Figure 3 The effects of orally administered CMC2.24 or placebo on numbers of severely inflamed gingival sites (GI $\geq 2$ ) at each time point (baseline, I, 2, and 3 months). Grey bar: Placebo group; black bar: CMC2.24 treatment group. Each value represents the mean (I39-I83 sites/per group) \pm S.E.M. *Indicates p<0.05, values at each time period compared to its own baseline. 


\section{Alveolar Bone Loss}

Consistent with the above described clinical parameters, radiographically assessed alveolar bone loss at the 3-month time point indicated that placebo administration produced no significant change in this important assessment of periodontal destruction. In contrast, $\mathrm{CMC} 2.24$ treatment produced a highly significant $(\mathrm{p}<0.001) 27 \%$ reduction in alveolar bone loss (Figure 5A and B).

\section{Gingival Crevicular Fluid (GCF)}

As indicated in Figure 6A, the pattern of change over time, for both the placebo and CMC2.24 groups, was similar to that for the clinical measurements of gingival inflammation and pocket depth (Figures 3 and 4). The GCF (Periotron ${ }^{\circledR}$ ) scores were significantly decreased in the CMC2.24 group by $32 \%$, compared to the placebo group, at the 3-month time period $(p<0.05)$ (Figure 6A). Moreover, compared to its own baseline, the 3-month regimen of CMC2.24 produced a similar level of reduction $(>30 \%)$ at the end of the experimental protocol which, unlike the placebo group, was also statistically significant $(\mathrm{p}<0.05)$. In contrast, the placebo-treated control group showed no pattern of change during the 3-month protocol.

Changes in IL-1 $\beta$ concentrations $(\mathrm{pg} / \mathrm{mL})$ appeared to be more variable, even at the baseline measurements (Figure 6B). The IL-1 $\beta$ concentration was significantly greater in the CMC2.24 group compared to the placebo control group $(p<0.05)$, prior to starting the experimental treatment protocol (baseline values), but did show a $43 \%$ reduction $(p<0.05)$ after 2 and 3 months of CMC2.24 treatment. It should be noted, however, that although the 2-month values for the placebo
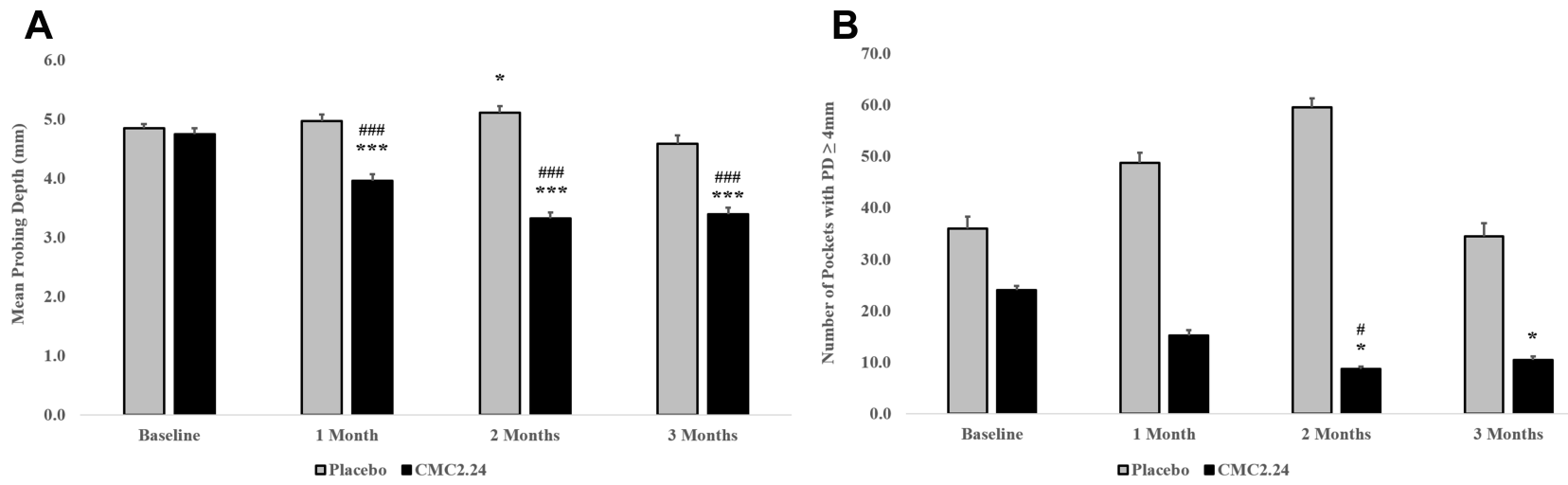

Figure 4 The effects of orally administered CMC2.24 or placebo on probing depth (PD) in dogs during a three-month protocol. Grey bar: Placebo group; black bar: CMC2.24 treatment group. (A) Pockets with baseline (time $=0$ ) probing depth $\geq 4 \mathrm{~mm}$ in posterior tooth sites were monitored at $\mathrm{I}$, 2 , and 3 months. Each value represents the mean (90-144 sites/per group) \pm S.E.M. ****Indicates $p<0.00$ I, values at each time period compared to its own baseline; ${ }^{\# \# I n d i c a t e s ~} \mathrm{p}<0.00 \mathrm{I}$, values compared to placebo at each time period. (B) Number of pockets with PD $\geq 4 \mathrm{~mm}$ were measured for baseline, I, 2, and 3-month time period. Each value represents the mean (35-238 sites/per group) \pm S.E.M. *Indicates $p<0.05$, values at each time period compared to its own baseline; ${ }^{\#}$ Indicates $p<0.05$, values compared to placebo at each time period.
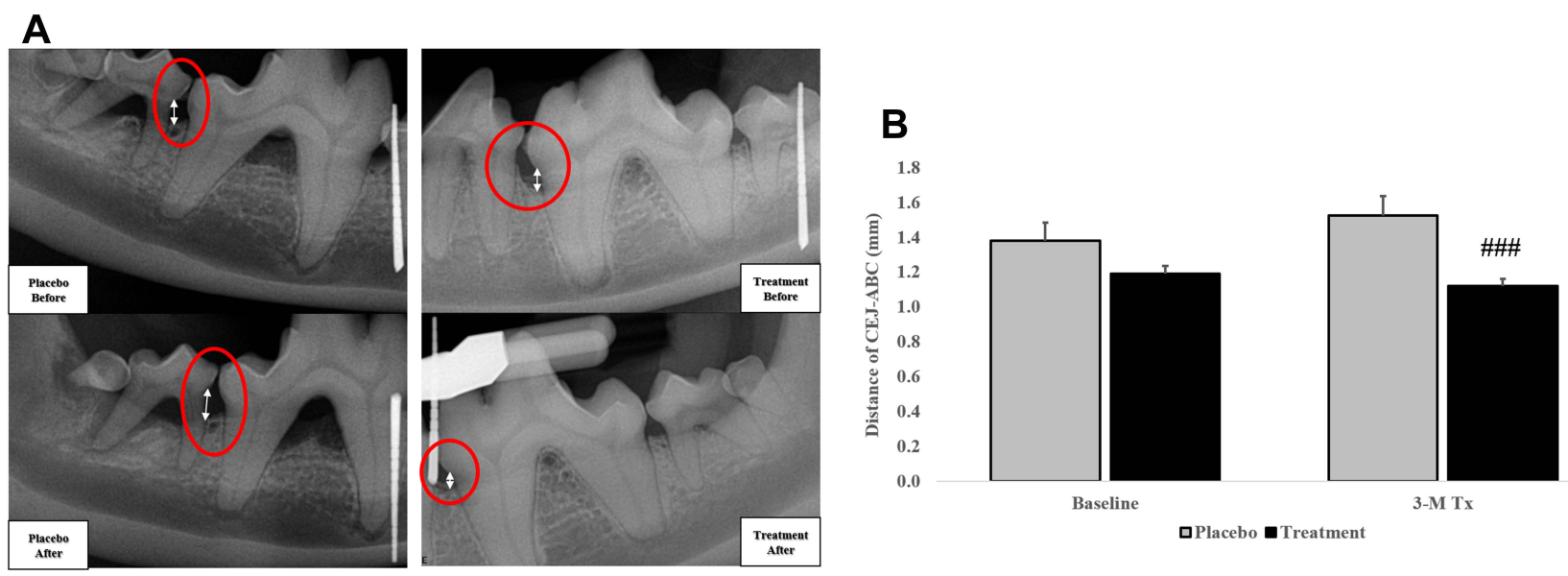

Figure 5 The distance $(\mathrm{mm})$ from cementoenamel junction (CEJ) to alveolar bone crest (ABC) was measured by radiography for CMC2.24 and placebo groups at baseline and 3 months. (A) Arrows in circles indicate the distance of alveolar bone loss. (B) Grey bar: Placebo group; black bar: CMC2.24 treatment group. Each value represents the

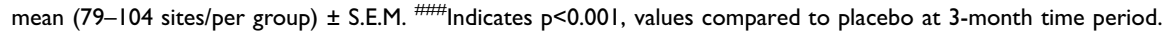


A

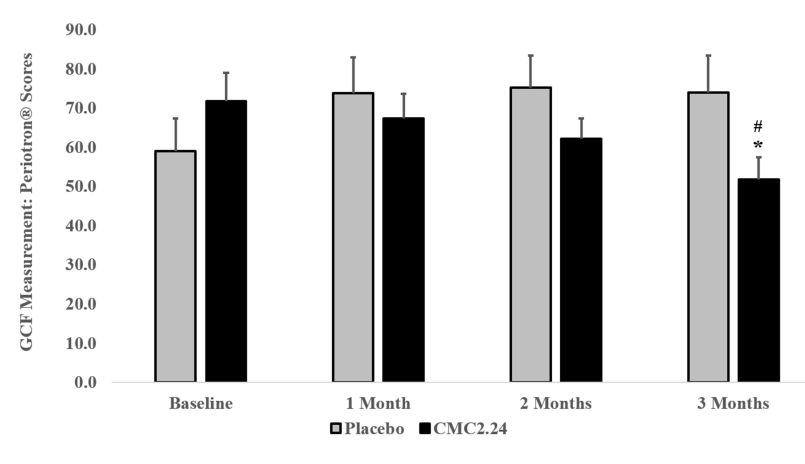

\section{B}

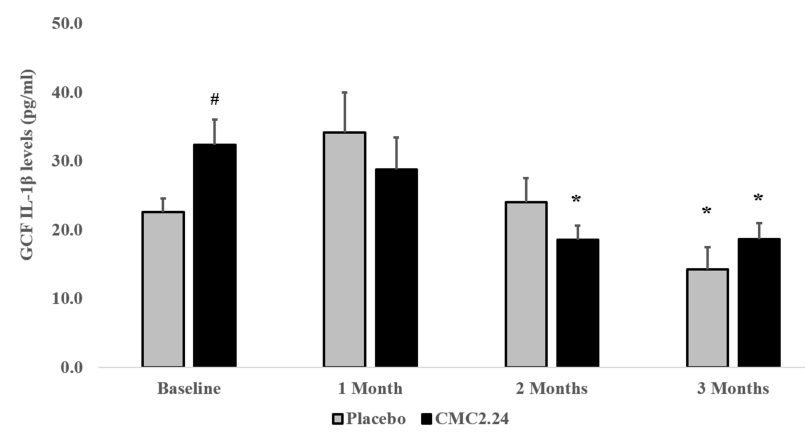

Figure 6 The effects of orally administered CMC2.24 or placebo on clinical and biochemical measurements of GCF in dogs during a three-month protocol. Grey bar: Placebo Group; black bar: CMC2.24 Treatment Group. (A). Each value represents the Mean (25-29 sites/per group) \pm S.E.M. *Indicates p<0.05, values at 3-month time period compared to its own baseline; ${ }^{\#}$ Indicates $p<0.05$, values compared to placebo at 3 months. (B). IL-I $\beta$ levels (pg/mL) in GCF were also measured at baseline, I, 2 , and 3 months. Each value represents the mean ( $n=4 /$ group) \pm S.E.M. *Indicates $p<0.05$, values at each time period compared to its own baseline; ${ }^{\#}$ Indicates $p<0.05$, values compared to placebo at each time period.

group were not different from its own baseline values, 3 months on placebo did show a significant reduction of IL-1 $\beta$ in the GCF samples (Figure 6B). Other inflammatory markers in the GCF, including IL-6, TNF- $\alpha$ and hs-CRP were all undetectable by ELISA measurements.

\section{Gingival Extracts}

Significant changes in levels of MMP-9 and MMP-2 in partially purified extracts of gingival tissues were seen at three months, the conclusion of the study (Figure 7A and B). As shown in a representative zymogram (Figure 7A), $92 \mathrm{kDa}$ gelatinase or pro-MMP-9 was clearly detectable in the gingival tissues of both groups of dogs; CMC2.24 treatment significantly reduced total-, pro-, and activatedforms of this collagenolytic neutral proteinase by $33 \%$ $(\mathrm{p}<0.005)$ for both total- and pro-forms, and by more than 90\% $(\mathrm{p}<0.001)$ for the activated form. A similar pattern of inhibition was seen for these 3 forms of MMP-2 by CMC2.24 treatment (Figure 7B), compared to placebo group, except that only the suppression of the activated-form of MMP-2 by this treatment was statistically significant $(\mathrm{p}<0.05)$.

The extracts of gingival tissues were also analyzed for the expression of cell-signaling molecules, TLR-2 (Figure 8A) and p38 MAPK (Figure 8B), by Western blot technique. ${ }^{36}$ CMC2.24 treatment significantly reduced TLR-2 $(\mathrm{p}<0.05)$ by $50.9 \%$, (TLR-4 also showed a trend of reduction, but this effect was not statistically significant; data not shown) and also decreased p38 MAPK $(\mathrm{p}<0.05)$ by $37.2 \%$, at the 3-month time period, compared to placebo.

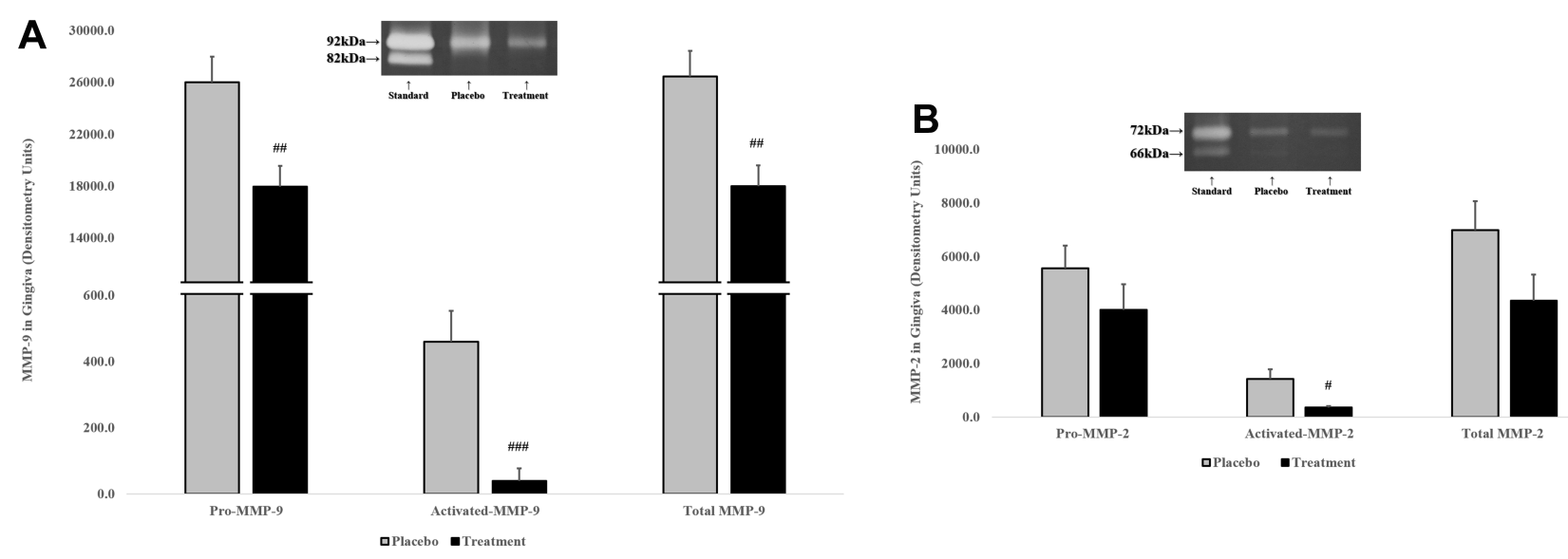

Figure 7 The effects of orally administered CMC2.24 or placebo on MMP-9 and MMP-2 in gingival extracts measured by gelatin zymography at three months. Grey bar: Placebo group; black bar: CMC2.24 treatment group. Each value represents the mean ( $\mathrm{n}=4$ samples/group) \pm S.E.M. (A) Pro-, activated-, and total-MMP-9 in gingival extracts

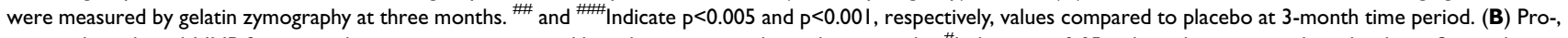
activated-, and total-MMP-2 in gingival extracts were measured by gelatin zymography at three months. ${ }^{\#}$ Indicates $p<0.05$, values also compared to placebo at 3-month time period. 

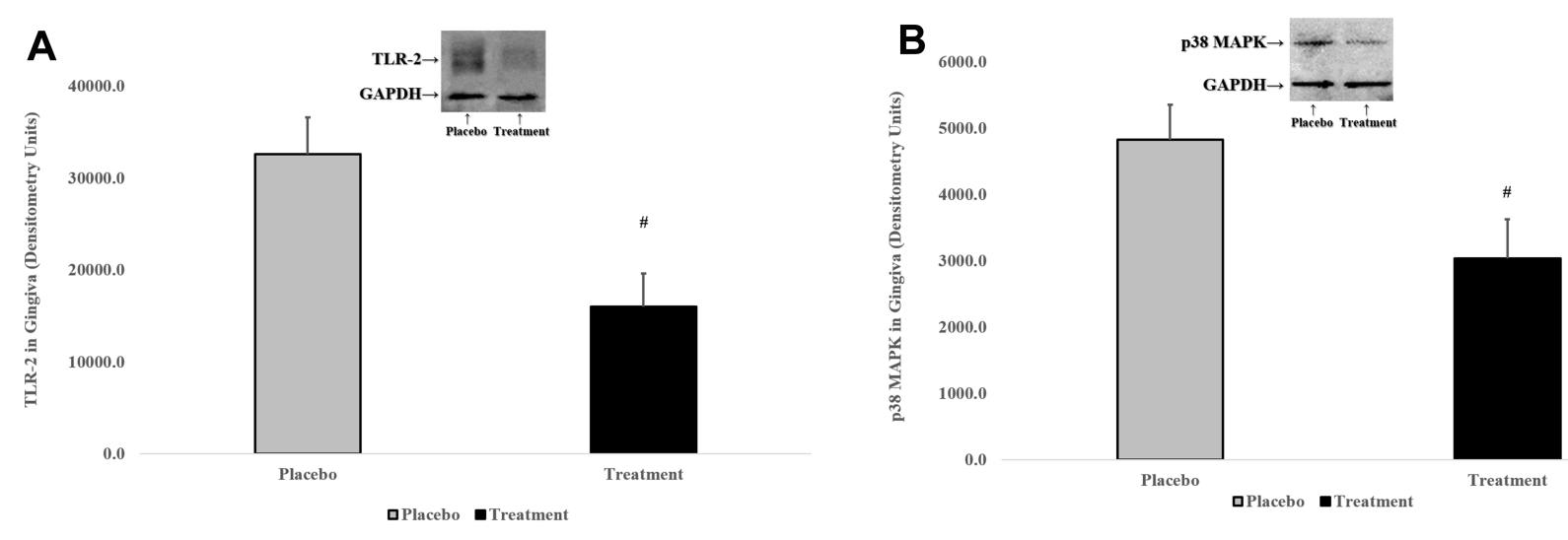

Figure 8 The effects of orally administered CMC2.24 or placebo on cell-signaling molecules in gingival extracts were measured by Western blot at three months. Grey bar: Placebo group; black bar: CMC2.24 treatment group. Each value represents the mean ( $\mathrm{n}=4$ samples/group) \pm S.E.M. (A) TLR-2 in gingival extracts. ${ }^{\#}$ Indicates $\mathrm{P}<0.05$, values compared to placebo at 3-month time period. (B) p38 MAPK in gingival extracts. "Indicates $p<0.05$, values compared to placebo at 3-month time period.

\section{Macrophage Cell Culture (ex-vivo)}

Monocyte/macrophages were isolated from peripheral blood samples of the dogs, treated in vivo either with CMC2.24 or placebo, at the 3 -month time period. These cells were then cultured ex-vivo for $18 \mathrm{hrs}$. CMC2.24 treatment essentially completely blocked the conversion of prointo smaller molecular weight activated-MMP-9 $(p<0.05)$. In contrast, in the placebo-treated dogs, although some of the pro-MMP-9 was found to be activated, most of the MMP-9 remained in the inactive, higher molecular weight (92 kDa) pro-form (Figure 9).

\section{Discussion}

Periodontitis is an extremely, perhaps the most, prevalent chronic inflammatory disease in both humans and $\operatorname{dogs}^{46,47}$ and, like humans, natural periodontitis in dogs is characterized by progressive destruction of connective tissues and alveolar bone. As is well known, this local disease is initiated by a persistent microbial insult, i. e., lipopolysaccharide (LPS)/endotoxin from anaerobic gram-negative bacteria such as Porphyromonas gingivalis, but largely attributed to an exuberant host response in susceptible individuals. ${ }^{48}$ LPS and other virulence factors stimulate the host's immune-inflammatory response by binding to Toll-like receptors (TLR-2 and/or TLR-4 induced by $P$. gingivalis; TLR-4 induced by E. coli ${ }^{49}$ ) which further activates the downstream cell-signaling molecules, especially nuclear factor kappa-light-chainenhancer of activated B cells (NF- $\mathrm{KB}$ ), and transcription through the protein kinase signaling transduction system. ${ }^{50}$ Research also showed the binding of the receptor activator of nuclear factor kappa-B ligand (RANKL) with RANK can also activate NF- $\kappa B .{ }^{51} \mathrm{NF}-\kappa \mathrm{B}$ transcription then upregulates multiple cellular signaling cascade events, such as the p38 MAPKs, which promote the expression of proinflammatory cytokines, (e.g., IL- $1 \beta$, TNF- $\alpha$, and IL-6), chemokines, MMPs (such as MMP-8, MMP-9, MMP-12 and MMP-13), and reactive oxygen species (e.g., superoxide anion, hypochlorous acid, hydroxyl anion). ${ }^{52}$ These inflammatory bio-active molecules are important mediators in the pathogenesis of periodontitis, which is characterized by the recruitment of neutrophils, macrophages, T-cells, B-cells and other inflammatory cells to the periodontium, followed by the destruction of the extracellular matrix, including the loss of alveolar bone. ${ }^{53,54}$

To develop optimally effective therapeutic strategies, suppression of the microbial biofilm is essential but insufficient; it is now recognized that HMT is also needed. However, only one host-modulator, a novel NONantimicrobial formulation of doxycycline (NAD), has been governmentally approved (US-FDA; also Canada and Europe Regulatory Agencies) as treatment (adjunctive to SRP) of human periodontal disease. An additional NAD, Orace $^{\circledR}$, which is an FDA-approved NON-antimicrobial medication for chronic inflammatory skin disease, acne rosacea, has been used "off-label" as an adjunct to SRP as well. ${ }^{9}$ And, finally, in considering the use of the NON-antibiotic properties of tetracyclines as host-modulators, one of the most potent of the chemically-modified tetracyclines, CMT3 has also shown evidence of safety and efficacy in cell and tissue culture, in vivo (rat models), and in clinical studies. ${ }^{9,12,55}$ This novel and potent MMP-inhibitor compound was tested in humans with Kaposi's Sarcoma and found to suppress neoplastic angiogenesis. ${ }^{55}$ More recently, Ryan et $\mathrm{al}^{56}$ described a pilot study in which a low dose of 


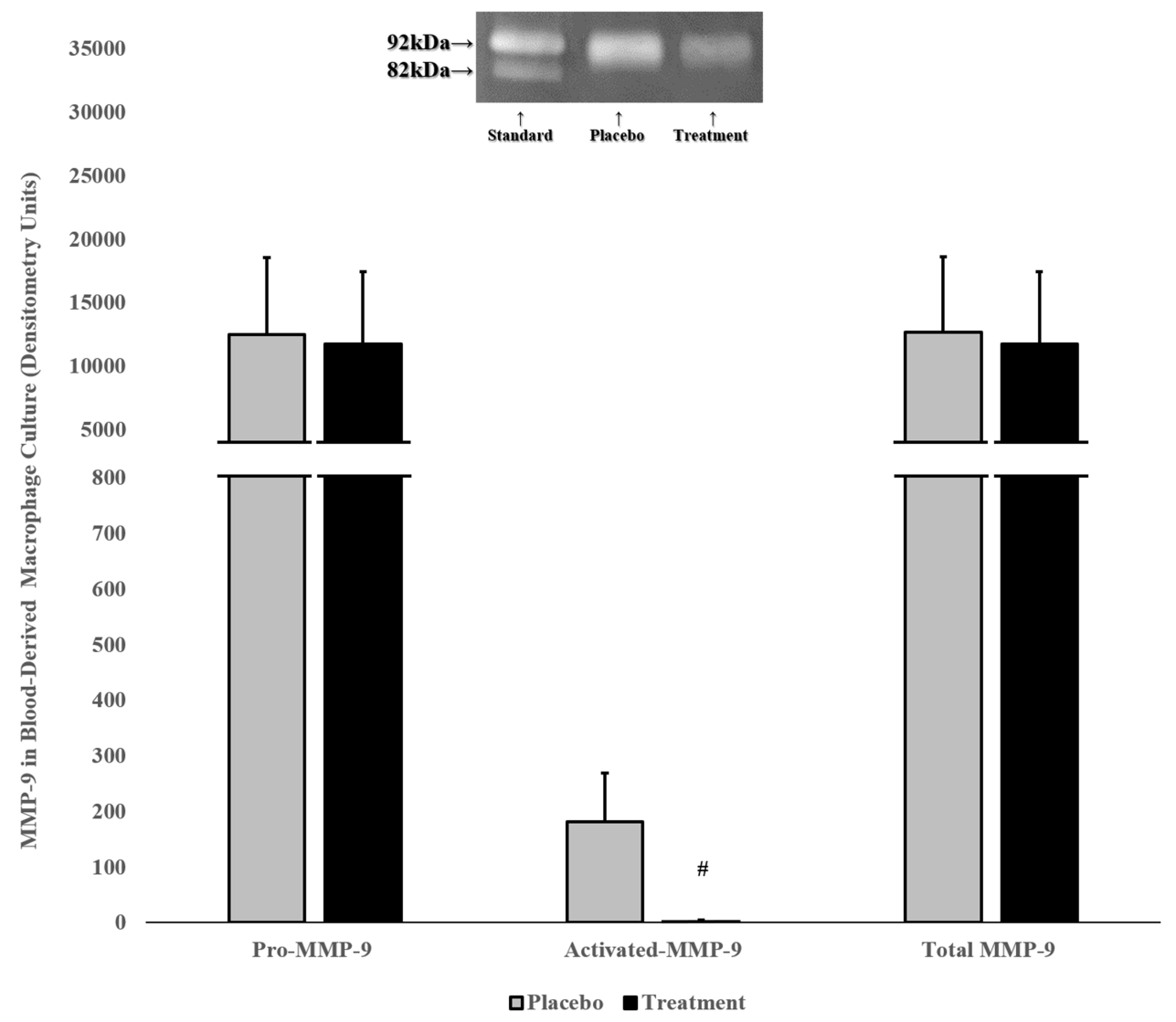

Figure 9 The effects of orally administered CMC2.24 or placebo on pro-, activated-, and total-MMP-9 in blood-derived monocyte/macrophage culture (ex-vivo) were detected by gelatin zymography at three months. Grey bar: Placebo group; black bar: CMC2.24 treatment group. Each value represents the mean ( $\mathrm{n}=4 /$ group) \pm S.E.M. \#Indicates $p<0.05$, values compared to placebo at 3-month time period.

CMT-3 (10 mg once/day) suppressed IL-1 $\beta$ and MMP-8 in the GCF of patients with chronic periodontitis. Although CMT-3 has been tested in human cells ${ }^{13,14}$ and in several human diseases, ${ }^{55,56}$ it has not yet been approved for clinical use.

More recently, we have proposed a newer therapeutic strategy which uses orally (systemically) administered CMC2.24, a novel chemically-modified curcumin which is modeled after the tetracyclines, but which has an enhanced $\mathrm{Ca}^{2+}$ and $\mathrm{Zn}^{2+}$ binding site; the latter involves a triketonic structure in its C-4 position, plus additional structural differences (see Figure 1). In this regard, CMC2.24 has also been tested in different models and conditions as we described before and shown to be effective in improving delayed wound healing, ${ }^{38}$ and reducing severe periodontitis as complications of uncontrolled diabetes in rats; ${ }^{35}$ it also reduced LPSenhanced periodontal disease in both normal and diabetic rats. ${ }^{32,36}$ Multiple mechanisms of action, exhibited by this novel compound CMC2.24, appear to be involved in suppressing periodontal tissue destruction in these animal models. In brief, these mechanisms include (but are not limited to) reducing pro-inflammatory mediator production (IL-1 $\beta$, IL-6, $\mathrm{TNF}-\alpha),{ }^{32,35,36}$ downregulating the transcription of inflammatory cell-signaling molecules (p65 NFkB and p38 MAPK), decreasing alveolar bone loss, ${ }^{36}$ and enhancing resolvin activity [Resolvin D1, a docosahexaenoic acid (DHA)]. ${ }^{34,35}$ These data also support the ability of this CMC2.24 to modulate intraand extra-cellular MMP-inhibitory mechanisms which are associated, at least in part, with the zinc-binding characteristics of this and related compounds. ${ }^{31}$

In the current study, we began to investigate the potential of $\mathrm{CMC} 2.24$ as a therapeutic adjunct to mechanical debridement to reduce naturally-occurring periodontitis in dogs, an animal model with characteristics similar to human periodontitis. This initial study showed that the 3-month regimen of this novel HMT significantly reduced inflammatory biomarkers and mediators, as well as reducing the severity of clinical measurements of periodontal disease. Specifically, the 3-month oral regimen of CMC2.24 was significantly effective at reducing probing depth and gingival inflammation (GI), as well as reducing radiographic alveolar bone loss, compared to placebo 
administration, even in the absence of a detectable effect on microbial biofilm accumulation. However, the other clinical parameters, including BOP, CAL and mobility scores, showed the trend of reduction, but were not statistically significant (data not shown). Regarding the biochemical mediators, there was a significant decrease in GCF IL-1 $\beta$ level in the treatment group at the 2-month time period, indicating CMC2.24 suppressed inflammatory mediator secretion. Moreover, CMC2.24 treatment inhibited the conversion of pro (inactive)- to activated-MMP-9 extracted from gingiva, and the effect was also seen in peripheral blood-derived monocyte/macrophages in cell culture. This novel treatment also reduced pathologically excessive levels of total-MMP-9 and activated-MMP-2 levels in the inflamed gingival tissues, further evidence of CMC2.24 suppression of host-mediated tissuedestructive activity. Since proteases such as trypsin and other factors such as ROS are capable of activating proMMPs, ${ }^{57,58}$ the suppression of these factors by CMC2.24 may provide, at least in part, additional mechanisms for reducing tissue breakdown. Furthermore, Western blot analysis of these gingival extracts showed that CMC2.24 attenuated the inflammatory signal cascade system by decreasing the expression levels of TLR-2 and p38 MAPK. There also appeared to be some reduction by CMC2.24, in the following molecular pathways, including: TLR-4, extracellular signal-regulated kinases (ERK1/ 2 MAP kinases, the classical MAP kinases), nicotinamide adenine dinucleotide phosphate oxidase 4 (NADPH oxidase 4), and p65 NFкB (data not shown). However, these effects were not statistically significant and require further investigation.

A separate study has been initiated to determine whether a short time period (e.g., 1-month treatment) would also be effective. In this regard, preliminary evidence in the dog model indicates that a 1-month protocol, although it did not result in clinical improvement, did reduce MMP-9 in peripheral blood (plasma) (data not shown). This ongoing preliminary study suggests that CMC2.24 is a potent inhibitor of MMPs and that this early effect, with longer periods of treatment, ultimately results in clinical improvements. These results will be published in a separate paper.

\section{Conclusion}

In summary, our results indicated that CMC2.24 can significantly reduce the active tissue-destructive phase of the inflammatory process during naturally-occurring periodontitis. The potential clinical efficacy of CMC2.24 was demonstrated by improvements in: (a) the clinical periodontal measurements; (b) the proinflammatory cytokines and collagenolytic MMPs; and (c) the transcription factors involved in the inflammatory signal cascade such as TLR-2 and p38 MAPK. It should also be pointed out that CMC2.24 was found to be safe as well as effective. There was no evidence of toxicity and no adverse events in the CMC2.24 treated dogs (or other animals, or in cell culture). ${ }^{30,35}$ These results, along with previous studies, support the potential of CMC2.24 as a novel adjunct to SRP for optimal management of periodontal disease.

\section{Acknowledgments}

This study was funded by NIDCR/NIH grant R42DE024946 and Traverse BioSciences, Inc. Authors would like to thank Rachel Kogan (Department of Biology, Stony Brook University, New York, USA), Akshani Patel (Department of Biology, Stony Brook University, New York, USA), Tyler Francisco (Department of Psychology, Stony Brook University, New York, USA), and Kai-Xi Lin (Department of Pharmacology, Stony Brook University, New York, USA) for their assistances to the dog study.

\section{Disclosure}

Lorne M. Golub is listed as an inventor on several related patents and these have been fully assigned to his institution, Stony Brook University, The State University of New York (SUNY). In the past, he received grants from Stony Brook University, Johnson \& Johnson Dental Care Inc., Collagenex Pharma, Inc., and from NY State Diabetes Assoc., but not during the conduct of the study. In addition, Dr. Lorne M. Golub also provided consulting in the past for Johnson \& Johnson Dental care Inc., and Collagernex Pharma Inc. Francis Johnson is also listed as an inventor on several related patents which have been fully assigned to Stony Brook University and to Chem-Master Int., Inc., on a shared basis. In addition, both Lorne M. Golub and Francis Johnson are minor shareholders in Traverse Biosciences, Inc., and Joseph Scaduto is the president and major shareholder in Traverse Biosciences Inc. They received grants from NIH/ NIDCR (Phase II STTR Award 2R42DE024946-02) and from Traverse Biosciences Inc. Also, Traverse Biosciences Inc. has exclusively licensed patents from the Research Foundation for the State University of New York (RF/ SUNY) covering the structure and use of the chemicallymodified curcumins for the purpose of commercialization in human and animal health. The authors report no other conflicts of interest in this work. 


\section{References}

1. Suzuki N, Yoneda M, Hirofuji T. Mixed red-complex bacterial infection in periodontitis. Int J Dent. 2013;2013:587279. doi:10.1155/2013/587279

2. Preshaw PM. Host response modulation in periodontics. Periodontol 2000. 2008;48:92-110. doi:10.1111/prd.2008.48.issue-1

3. Van Dyke TE. Commentary: periodontitis is characterized by an immuno-inflammatory host-mediated destruction of bone and connective tissues that support the teeth. J Periodontol. 2014;85(4):509-511. doi:10.1902/jop.2014.130701

4. Preshaw PM, Taylor JJ. How has research into cytokine interactions and their role in driving immune responses impacted our understanding of periodontitis? J Clin Periodontol. 2011;38(Suppl 11):60-84.

5. Ballini ACS, Farronato D, Cirulli N, et al. Periodontal disease and bone pathogenesis: the crosstalk between cytokines and porphyromonas gingivalis. J Biol Regul Homeost Agents. 2015;29(2):273-281.

6. Golub LM, Lee H-M. Periodontal therapeutics: current host-modulation agents and future directions. Periodontol 2000. 2020;82(1):186-204.

7. Golub LM, Lee HM, Ryan ME, Giannobile WV, Payne J, Sorsa T. Tetracyclines inhibit connective tissue breakdown by multiple non-antimicrobial mechanisms. Adv Dent Res. 1998;12(2):12-26. doi: $10.1177 / 08959374980120010501$

8. Golub LM, Wolff M, Roberts S, Lee HM, Leung M, Payonk GS. Treating periodontal diseases by blocking tissue-destructive enzymes. $J$ Am Dent Assoc. 1994;125(2):163-169; discussion 169-171. doi:10.14219/jada.archive.1994.0261

9. Golub LM, Elburki MS, Walker C, et al. Non-antibacterial tetracycline formulations: host-modulators in the treatment of periodontitis and relevant systemic diseases. Int Dent J. 2016;66(3):127-135. doi:10.1111/idj.2016.66.issue-3

10. Gu Y, Walker C, Ryan ME, Payne JB, Golub LM. Non-antibacterial tetracycline formulations: clinical applications in dentistry and medicine. J Oral Microbiol. 2012;4:19227.

11. Sadowsky D, Nieman G, Barclay D, et al. Impact of chemically-modified tetracycline 3 on intertwined physiological, biochemical, and inflammatory networks in porcine sepsis/ARDS. Int J Burns Trauma. 2015;5(1):22-35.

12. Lee HM, Golub LM, Cao J, et al. CMT-3, a non-antimicrobial tetracycline (TC), inhibits MT1-MMP activity: relevance to cancer. Curr Med Chem. 2001;8(3):257-260. doi:10.2174/0929867013373660

13. Roy SK, Kubiak BD, Albert SP, et al. Chemically modified tetracycline 3 prevents acute respiratory distress syndrome in a porcine model of sepsis + ischemia/reperfusion-induced lung injury. Shock. 2012;37(4):424-432. doi:10.1097/SHK.0b013e318245f2f9

14. Gu Y, Lee HM, Simon SR, Golub LM. Chemically modified tetracycline-3 (CMT-3): a novel inhibitor of the serine proteinase, elastase. Pharmacol Res. 2011;64(6):595-601. doi:10.1016/j.phrs.2011.05.011

15. Gu Y, Lee HM, Golub LM, Sorsa T, Konttinen YT, Simon SR. Inhibition of breast cancer cell extracellular matrix degradative activity by chemically modified tetracyclines. Ann Med. 2005;37 (6):450-460. doi:10.1080/07853890500300386

16. Trachtman H, Futterweit S, Greenwald R, et al. Chemically modified tetracyclines inhibit inducible nitric oxide synthase expression and nitric oxide production in cultured rat mesangial cells. Biochem Biophys Res Commun. 1996;229(1):243-248. doi:10.1006/bbrc.1996.1787

17. Serhan CN, Hong S, Gronert K, et al. Resolvins: a family of bioactive products of omega-3 fatty acid transformation circuits initiated by aspirin treatment that counter proinflammation signals. J Exp Med. 2002;196(8):1025-1037. doi:10.1084/jem.20020760

18. Gyurko R, Van Dyke TE. The role of polyunsaturated omega-3 fatty acid eicosapentaenoic acid-derived resolvin E1 (RvE1) in bone preservation. Crit Rev Immunol. 2014;34(4):347-357. doi:10.1615/ CritRevImmunol.2014009982
19. Serhan CN. Systems approach with inflammatory exudates uncovers novel anti-inflammatory and pro-resolving mediators. Prostaglandins Leukot Essent Fatty Acids. 2008;79(3-5):157-163. doi:10.1016/j. plefa.2008.09.012

20. Rey C, Nadjar A, Buaud B, et al. Resolvin D1 and E1 promote resolution of inflammation in microglial cells in vitro. Brain Behav Immun. 2016;55:249-259. doi:10.1016/j.bbi.2015.12.013

21. Kain V, Ingle KA, Colas RA, et al. Resolvin D1 activates the inflammation resolving response at splenic and ventricular site following myocardial infarction leading to improved ventricular function. $J \mathrm{Mol}$ Cell Cardiol. 2015;84:24-35. doi:10.1016/j.yjmcc.2015.04.003

22. Fredman G, Ozcan L, Spolitu S, et al. Resolvin D1 limits 5-lipoxygenase nuclear localization and leukotriene B4 synthesis by inhibiting a calcium-activated kinase pathway. Proc Natl Acad Sci USA. 2014;111(40):14530-14535. doi:10.1073/pnas.1410851111

23. Liao Z, Dong J, Wu W, et al. Resolvin D1 attenuates inflammation in lipopolysaccharide-induced acute lung injury through a process involving the PPARgamma/NF-kappaB pathway. Respir Res. 2012;13:110. doi:10.1186/1465-9921-13-110

24. Croasdell A, Sime PJ, Phipps RP. Resolvin D2 decreases TLR4 expression to mediate resolution in human monocytes. FASEB $J$. 2016;30(9):3181-3193. doi:10.1096/fj.201600375R

25. Ohira T, Arita M, Omori K, Recchiuti A, Van Dyke TE, Serhan CN. Resolvin E1 receptor activation signals phosphorylation and phagocytosis. J Biol Chem. 2010;285(5):3451-3461. doi:10.1074/ jbc.M109.044131

26. Arita M, Ohira T, Sun YP, Elangovan S, Chiang N, Serhan CN. Resolvin E1 selectively interacts with leukotriene B4 receptor BLT1 and chemR23 to regulate inflammation. J Immunol. 2007;178 (6):3912-3917. doi:10.4049/jimmunol.178.6.3912

27. Ariel A, Serhan CN. Resolvins and protectins in the termination program of acute inflammation. Trends Immunol. 2007;28(4):176-183. doi:10.1016/j.it.2007.02.007

28. Golub LM, Ryan ME, Williams RC. Modulation of the host response in the treatment of periodontitis. Dent Today. 1998;17(10):102-106, 108-109.

29. Lee HM, Ciancio SG, Tuter G, Ryan ME, Komaroff E, Golub LM. Subantimicrobial dose doxycycline efficacy as a matrix metalloproteinase inhibitor in chronic periodontitis patients is enhanced when combined with a non-steroidal anti-inflammatory drug. J Periodontol. 2004;75(3):453-463. doi:10.1902/jop.2004.75.3.453

30. Zhang Y, Gu Y, Lee HM, et al. Design, synthesis and biological activity of new polyenolic inhibitors of matrix metalloproteinases: a focus on chemically-modified curcumins. Curr Med Chem. 2012;19 (25):4348-4358. doi:10.2174/092986712802884295

31. Zhang Y, Golub L M, Johnson F, Wishnia A. pKa, zinc- and serum albumin-binding of curcumin and two novel biologically- active chemically-modified curcumins. Curr Med Chem. 2012;19 (25):4367-4375. doi:10.2174/092986712802884240

32. Elburki MS, Rossa C, Guimaraes MR, et al. A novel chemically modified curcumin reduces severity of experimental periodontal disease in rats: initial observations. Mediators Inflamm. 2014;2014:959471. doi:10.1155/2014/959471

33. Elburki MS, Moore DD, Terezakis NG, et al. A novel chemically modified curcumin reduces inflammation-mediated connective tissue breakdown in a rat model of diabetes: periodontal and systemic effects. J Periodontal Res. 2017;52(2):186-200. doi:10.1111/ jre.2017.52.issue-2

34. Deng J, Gu Y, Lee HM, Raja V, Johnson F, Golub LM. Novel modified-curcumin: resolution of cytokines and MMPs in cell culture. J Dent Res. 2018;97(Special Issue A):0129.

35. Gu Y, Deng J, Lee HM, et al. Chemically-modified-curcumin: resolvin activity in experimental diabetes. J Dent Res. 2017;96(Special Issue A):1173. doi:10.1177/0022034516680771 
36. Elburki MS, Rossa C Jr., Guimaraes-Stabili MR, et al. A chemically modified curcumin (CMC 2.24) inhibits nuclear factor kappaB activation and inflammatory bone loss in murine models of LPS-induced experimental periodontitis and diabetes-associated natural periodontitis. Inflammation. 2017;40(4):1436-1449. doi:10.1007/ s10753-017-0587-4

37. Elburki MS. A Novel Chemically Modified Curcumin as a Pleiotropic MMP-Inhibitor: Therapeutic Potential in Locally- and SystemicallyInduced Periodontal (And Other) Connective Tissue Breakdown. University Libraries on behalf of The Graduate School at Stony Brook University: Oral Biology and Pathology, Stony Brook University; 2015.

38. Zhang Y, McClain SA, Lee HM, et al. A novel chemically modified curcumin "normalizes" wound-healing in rats with experimentally induced type $\mathrm{i}$ diabetes: initial studies. $J$ Diabetes Res. 2016;2016:5782904. doi:10.1155/2016/5782904

39. $\mathrm{Xu} \mathrm{L}, \mathrm{Yu} \mathrm{Z}$, Lee HM, et al. Characteristics of collagenase-2 from gingival crevicular fluid and peri-implant sulcular fluid in periodontitis and peri-implantitis patients: pilot study. Acta Odontol Scand. 2008;66(4):219-224. doi:10.1080/00016350802183393

40. Golub LM, Lee HM, Stoner JA, et al. Subantimicrobial-dose doxycycline modulates gingival crevicular fluid biomarkers of periodontitis in postmenopausal osteopenic women. J Periodontol. 2008;79 (8):1409-1418. doi:10.1902/jop.2008.070623

41. White SCPM. Oral Radiology: Principles and Interpretation. Elsevier Health Sciences; 2014.

42. Jeffcoat MK, Reddy MS. Advances in measurements of periodontal bone and attachment loss. Monogr Oral Sci. 2000;17:56-72.

43. Zaki HA, Hoffmann KR, Hausmann E, Scannapieco FA. Is radiologic assessment of alveolar crest height useful to monitor periodontal disease activity? Dent Clin North Am. 2015;59(4):859-872. doi:10.1016/j.cden.2015.06.009

44. Liao G, Simone J, Simon SR. Paracrine downregulation of Fc gamma RIII in human monocyte-derived macrophages induced by phagocytosis of nonopsonized particles. Blood. 1994;83(8):2294-2304. doi:10.1182/blood.V83.8.2294.2294

45. Golub LM, Ramamurthy NS, Llavaneras A, et al. A chemically modified nonantimicrobial tetracycline (CMT-8) inhibits gingival matrix metalloproteinases, periodontal breakdown, and extra-oral bone loss in ovariectomized rats. Ann NY Acad Sci. 1999;878:290-310. doi:10.1111/j.1749-6632.1999.tb07691.x

46. Albuquerque C, Morinha F, Requicha J, et al. Canine periodontitis: the $\operatorname{dog}$ as an important model for periodontal studies. Vet J. 2012;191(3):299-305. doi:10.1016/j.tvj1.2011.08.017
47. Nazir MA. Prevalence of periodontal disease, its association with systemic diseases and prevention. Int $J$ Health Sci (Qassim). 2017;11(2):72-80.

48. Yimam M, Brownell L, Do SG, et al. Protective Effect of UP446 on Ligature-Induced Periodontitis in Beagle Dogs. Dent J (Basel). 2019;7:2.

49. Yoshioka H, Yoshimura A, Kaneko T, Golenbock DT, Hara Y. Analysis of the activity to induce toll-like receptor (TLR)2- and TLR4-mediated stimulation of supragingival plaque. J Periodontol. 2008;79(5):920-928. doi:10.1902/jop.2008.070516

50. Mogensen TH. Pathogen recognition and inflammatory signaling in innate immune defenses. Clin Microbiol Rev. 2009;22(2):240-273. doi:10.1128/CMR.00046-08

51. Matarese G, Curro M, Isola G, et al. Transglutaminase 2 up-regulation is associated with RANKL/OPG pathway in cultured HPDL cells and THP-1-differentiated macrophages. Amino Acids. 2015;47(11):2447-2455. doi:10.1007/s00726-015-2039-5

52. Nussbaum G, Shapira L. How has neutrophil research improved our understanding of periodontal pathogenesis? J Clin Periodontol. 2011;38(Suppl 11):49-59. doi:10.1111/jcpe.2011.38.issue-s11

53. Tornatore L, Thotakura AK, Bennett J, Moretti M, Franzoso G. The nuclear factor kappa B signaling pathway: integrating metabolism with inflammation. Trends Cell Biol. 2012;22(11):557-566. doi:10.1016/j.tcb.2012.08.001

54. Li Q, Yu H, Zinna R, et al. Silencing mitogen-activated protein kinase-activated protein kinase-2 arrests inflammatory bone loss. J Pharmacol Exp Ther. 2011;336(3):633-642. doi:10.1124/jpet.110. 172395

55. Dezube BJ, Krown SE, Lee JY, Bauer KS, Aboulafia DM. Randomized phase II trial of matrix metalloproteinase inhibitor COL-3 in AIDS-related Kaposi's sarcoma: an AIDS malignancy consortium study. J Clin Oncol. 2006;24(9):1389-1394. doi:10.12 00/JCO.2005.04.2614

56. Ryan ME, Lee HM, Tenzler R, et al. Effects of short-term COL-3 on local biomarkers of periodontitis. J Dent Res. 2008;87(Special Issue 0040).

57. Nyberg P, Moilanen M, Paju A, et al. MMP-9 activation by tumor trypsin-2 enhances in vivo invasion of human tongue carcinoma cells. J Dent Res. 2002;81(12):831-835. doi:10.1177/154405910208101207

58. Ramamurthy NS, Vernillo AT, Greenwald RA, et al. Reactive oxygen species activate and tetracyclines inhibit rat osteoblast collagenase. $J$ Bone Miner Res. 1993;8(10):1247-1253. doi:10.1002/jbmr.5650081013

59. Hefti AF, Preshaw PM. Examiner alignment and assessment in clinical periodontal research. Periodontol 2000. 2012;59(1):41-60. doi:10.1111/prd.2012.59.issue-1
Journal of Experimental Pharmacology

\section{Publish your work in this journal}

The Journal of Experimental Pharmacology is an international, peerreviewed, open access journal publishing original research, reports, reviews and commentaries on all areas of laboratory and experimental pharmacology. The manuscript management system is completely online and includes a very quick and fair peer-review system. Visit http://www.dovepress.com/testimonials.php to read real quotes from published authors. 